\title{
Prophylactic administration of L-arginine improves the intestinal barrier function after mesenteric ischaemia
}

\author{
R Schleiffer, F Raul
}

\begin{abstract}
Background-Ischaemia/reperfusion (I/R) of the intestine causes mucosal injury associated with a high death rate in rats. Aim-To investigate whether nitric oxide (NO) might be implicated in the recovery of the intestinal mucosa after ischaemic insult.

Methods-Wistar rats were subjected to mesenteric artery occlusion for 90 minutes. The animals were given either L-arginine, the substrate of NO synthase, or molsidomine, a NO donor. The controls received casein hydrolysate. The compounds were administered by gavage 19,16 , and 1.5 hours before ischaemia. Mucosal barrier permeability and cGMP content were determined 24 hours after ischaemia.

Results-Survival after I/R was $\mathbf{5 0 \%}$ in the control group. Animals treated with L-arginine or molsidomine exhibited a higher survival rate $(70 \%$ and $83 \%$ respectively). Mucosal barrier permeability was decreased in rats receiving $L$-arginine or molsidomine compared with controls $(4 \cdot 0$ $(0.9)$ and $2.6(0.6) v 11.2(1.6){ }^{14} \mathrm{C}-\mathrm{PEG}$ pmol/segment, $p<0.05)$. Increased cGMP content was seen in the mucosa of the L-arginine group.

Conclusion-The findings suggest that pretreatment with L-arginine or molsidomine ameliorates survival after intestinal I/R and improves mucosal barrier function.
\end{abstract}

(Gut 1996; 39: 194-198)

Keywords: nitric oxide, ischaemia/reperfusion, intestine, mucosal barrier permeability.

It has clearly been shown in animals that morphological and functional injury of the intestinal mucosa occurs during ischaemia and is exacerbated after re-establishment of tissue perfusion. ${ }^{1}$ This injury includes mucosal barrier disruption leading to increased mucosal and vascular permeability, bacterial translocation, and a high death rate. ${ }^{2-4}$ It has been proposed that most of the mucosal injury resulting from ischaemia/reperfusion ( $I / R)$ is mediated by production and release of reactive oxygen derived free radicals when hypoxic tissues are reoxygenated during reperfusion. ${ }^{5}$

Mucosal functions are spontaneously restored within hours or days during reperfusion depending on the duration and the severity of the mesenteric ischaemic period. ${ }^{67}$
Little is known about the mechanisms that contribute to the recovery of intestinal mucosal integrity after ischaemic insult. Several approaches have been used to reduce $I / R$ injury of the intestinal mucosa and to accelerate regeneration of mucosal functions after $I / R$. Among these are administration of free radical scavengers, ${ }^{89}$ inhibition of xanthine oxidase, ${ }^{10}$ neutrophil depletion, ${ }^{11} 12$ inhibition of leucocyte endothelial adherence, ${ }^{913}$ administration of platelet activating factor (PAF) antagonists, ${ }^{14}$ intraluminal oxygenation. ${ }^{15} \mathrm{~A}$ study performed in our laboratory showed that pretreatment with L-arginine accelerated the recovery of intestinal morphology and hydrolase activities after ischaemic insult in rats. ${ }^{16}$ These results suggest that NO might participate in the recovery of mucosal function after $\mathrm{I} / \mathrm{R}$. This conclusion is consistent with the data reporting that administration of exogenous sources of NO during $\mathrm{I} / \mathrm{R}$ protects against mucosal barrier dysfunction ${ }^{4} 17$ and with data demonstrating that the inhibition of NO production exacerbates intestinal damage induced by endotoxic shock ${ }^{18}$ or PAF. ${ }^{19}$

The objective of this study was to extend the possible contribution of NO in the regeneration of mucosal function by examining the effects of NO on intestinal barrier permeability in the postischaemic intestine. This was accomplished by determining the effect of enteral pretreatment with the NO precursor Larginine, the anti-anginal drug and $\mathrm{NO}$ donor molsidomine, and the NO biosynthesis inhibitor L-NAME, on intestinal lumen to blood fluxes of labelled polyethylene glycol 4000 ( $\left.{ }^{14} \mathrm{C}-\mathrm{PEG}\right)$.

As NO activates guanylate cyclase and increases cGMP formation, ${ }^{20}$ which mainly account for the NO effects, ${ }^{21}$ we determined intestinal mucosal cGMP content. As an index of intestinal function, we measured hydrolase activities in the mucosa.

\section{Methods}

Animals

Male Wistar rats weighing 360-430 g (Laboratoires Janvier, France) and fed a standard diet (A04 from UAR, Villemoisson/Orge, France) were used. The animals were deprived of food 24 hours before surgery and during the whole experiment but were allowed free access to drinking water. The animals were assigned to one of the four groups: (1) casein-I/R (control) rats were given casein hydrolysate $(0.8 \mathrm{~g} / \mathrm{kg} \mathrm{wt})$, (2) L-arginine-I/R rats were 
given L-arginine, the substrate of NO $(0.8 \mathrm{~g} / \mathrm{kg}$ wt), (3) molsidomine-I/R rats were given molsidomine, a NO donor (12 mg/kg wt) at a dose expected to result in similar haemodynamic effects to L-arginine ( $R$ Henning, personal communication), and (4) L-NAME-I/R rats were given $\mathrm{N}^{\mathrm{G}}$-nitro-L-arginine methyl ester (L-NAME), an inhibitor of NO biosynthesis $(50 \mathrm{mg} / \mathrm{kg} \mathrm{wt})$.

An additional group of sham operated rats were given casein hydrolysate but were not subjected to ischaemia.

Compounds were administered by gavage 19,16 , and 1.5 hours before sham surgery or ischaemia.

\section{Ischaemia procedure}

The rats were anaesthetised by intraperitoneal injection of ketamine (Imalgene 1000, 150 $\mu \mathrm{l} / 100 \mathrm{~g} \mathrm{wt})$. After induction of anaesthesia, the rats underwent midline laparatomy and the intestine was exposed. Inferior mesenteric artery was isolated near its aortic origin and occluded with an arterial bulldog clamp. Collateral blood flow interruption was achieved by ligating the right colonic artery and the jejunal arcades just proximal to the point of the mesenteric artery occlusion as described by Megison et al. ${ }^{22}$ In the sham operated rats, the mesenteric artery and collateral vessels were isolated in a similar fashion but not occluded. The intestine was replaced into the peritoneal cavity for the duration of ischaemic period. The animals were placed under a heating lamp to maintain body temperature at $37^{\circ} \mathrm{C}$. After 90 minutes, the arterial clamp was removed and the abdomen closed. The animals were then placed in plastic cages and mortality observed for each group.

\section{Determination of mucosal permeability}

Permeability of the mucosal barrier was assessed by measuring the lumen to blood fluxes of ${ }^{14} \mathrm{C}-\mathrm{PEG}$ using a modification of the technique described by Winne and Görig. ${ }^{23}$ Briefly, 24 hours after the beginning of intestinal reperfusion the rats were anaesthetised by intraperitoneal injection of ethyl carbamate $(1 \mathrm{ml} / 100 \mathrm{~g} \mathrm{wt})$. A catheter was inserted into the left jugular vein. The intestine was then exposed after a midline laparotomy. The in situ length of the jejunoileum was measured using a thread placed along its curved axis. The jejunoileum was cross sectioned in its middle and a $5 \mathrm{~cm}$ length segment just above the section was ligated at the two extremities with a thread. The rat was then placed into a box, which was kept at $37^{\circ} \mathrm{C}$ and dampened by circulating water. The exposed intestinal segment was covered with saline soaked gauze to prevent dessication. Heparin (600 U/kg wt) was then injected through the jugular vein. The mesenteric vein draining the isolated intestinal segment was cannulated (Polyethylene Biotrol $0.96 / 0.58 \mathrm{~mm}$ ). To collect only the venous blood from the isolated intestinal segment, the main mesenteric vein below the segment was ligated as well as the collateral veins. The venous effluent was allowed to drain freely and was collected at intervals of two minutes into $2 \mathrm{ml}$ calibrated tubes. The blood loss was compensated by jugular infusion of fresh heparinised rat blood. After stabilisation of the mesenteric venous flow rate the isolated intestinal segment was intraluminally injected with $0.5 \mathrm{ml}$ of Krebs-Ringer solution containing ${ }^{14} \mathrm{C}-\mathrm{PEG}$ (for composition see below). The blood samples were centrifugated and the plasma ${ }^{14} \mathrm{C}-\mathrm{PEG}$ activity quantified by liquid scintillation counting. In all rats the time course of plasma ${ }^{14} \mathrm{C}-\mathrm{PEG}$ concentration showed a plateau within six to eight minutes after the beginning of blood collection (data not shown). For each two minute time period, mucosal permeability was calculated based on the mesenteric venous flow rate and plasma ${ }^{14} \mathrm{C}-\mathrm{PEG}$ concentration. For comparisons, ${ }^{14} \mathrm{C}-\mathrm{PEG}$ permeability was calculated for the integrated first 10 minute time period. The values were expressed in pmol/segment.

Venous flow rate was determined volumetrically for each two minute time interval.

\section{Determination of mucosal hydrolase activities and cGMP content}

Before permeability measurement, a $20 \mathrm{~cm}$ intestinal segment, just below to the mid jejunoileum section, was resected. Immediately after resection, the segment was flushed with ice cold $\mathrm{NaCl} 0.9 \%$ and the mucosa scrapped off with a glass slide. The tissue was then separated into two moities, weighed, placed in a plastic tube, immediately frozen in liquid hydrogen, and stored at $-70^{\circ} \mathrm{C}$ until biochemical determinations.

After mucosal homogenisation in mannitol (50 mmol/l) and $2 \mathrm{mmol} / /$ TRIS ( $\mathrm{pH} 7 \cdot 1$ ), sucrase activity was determined according to the method of Dahlqvist, ${ }^{24}$ and aminopeptidase activity using L-alanine-p-nitroanilide as substrate. ${ }^{25}$ For cGMP determination, the mucosa was homogenised in $1 \mathrm{ml}$ of $\mathrm{HCl}(0 \cdot 1$ $\mathrm{N})$ and centrifugated at $10000 \mathrm{~g}$ for 10 minutes at $4^{\circ} \mathrm{C}$. The supernatants were stored at $-70^{\circ} \mathrm{C}$ until cGMP assay. ${ }^{2627}$

\section{Chemicals}

${ }^{14} \mathrm{C}-\mathrm{PEG}$ was purchased from Amersham (Buckinghamshire, UK). The Krebs-Ringer solution contained (in mmol/l) $116 \mathrm{NaCl}, 6$ $\mathrm{KCl}, 25 \mathrm{NaHCO}_{3}, 1.8 \mathrm{CaCl}_{2}, 1.2 \mathrm{NaH}_{2} \mathrm{PO}_{4}$, and 27.7 glucose, with osmolality of 300 mosml/1, and $67 \mu \mathrm{Ci} / 1$ of ${ }^{14} \mathrm{C}-\mathrm{PEG}$. Casein hydrolysate, $\mathrm{L}$-arginine, and $\mathrm{NG}^{\mathrm{G}}$-nitro-L-arginine methyl ester (L-NAME), an inhibitor of NO biosynthesis, were obtained from Sigma. The nitrovasodilator molsidomine, which generates NO, was supplied from Cassella AG (Frankfurt, Germany). Compounds given by gavage were dissolved in distilled water immediately before use and were given in a volume of $5 \mathrm{ml}$.

\section{Statistics}

All numerical data were reported as mean 
Figure 1: Effect of pretreatment with casein hydrolysate (Cas), Larginine ( $L$-arg), and molsidomine (Mol) on survival rate of rats subjected to ischaemia/reperfusion.

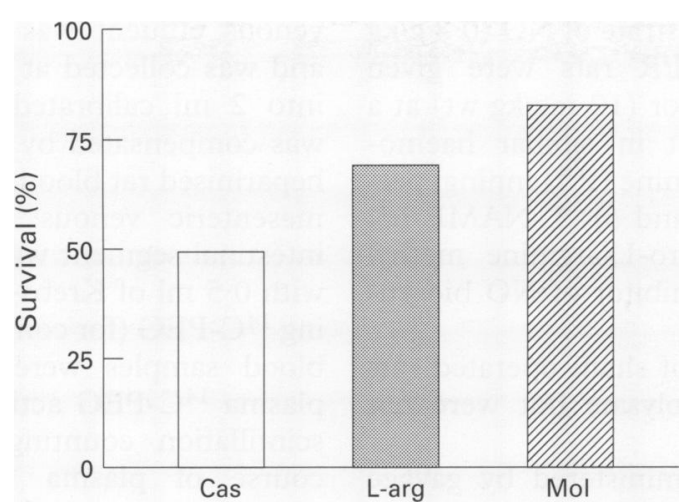

(SEM) values. Statistical comparisons were performed using ANOVA followed by Student's $t$ test and Neuman-Keuls test, with values of $\mathrm{p}<0.05$ accepted as significant.

\section{Results}

Mortality

All animals (five of five) survived in the sham operated group. Survival of the animals in the casein-I/R group was $50 \%$ (eight of 16 ) versus $67 \%$ (six of nine) in the L-arginine and $83 \%$ (five of six) in the molsidomine-I/R groups (Fig 1). All animals (six of six) in the L-NAME-I/R group died between six to 24 hours after the onset of reperfusion.

\section{Mesenteric venous blood flow}

Baseline mesenteric venous blood flow rates (VBFR) in the L-arginine-I/R and molsidomine-I/R groups were higher compared with casein-I/R group (Fig 2). VBFR values in the L-arginine-I/R and molsidomine-I/R groups were not different from that obtained in the sham group $(0.27(0.05) \mathrm{ml} / \mathrm{min}$, $\mathrm{n}=4)$.

\section{Intestinal barrier permeability}

The intestinal barrier permeability, as measured by ${ }^{14} \mathrm{C}-\mathrm{PEG}$ absorption, for the three groups is shown in Figure 3. Animals

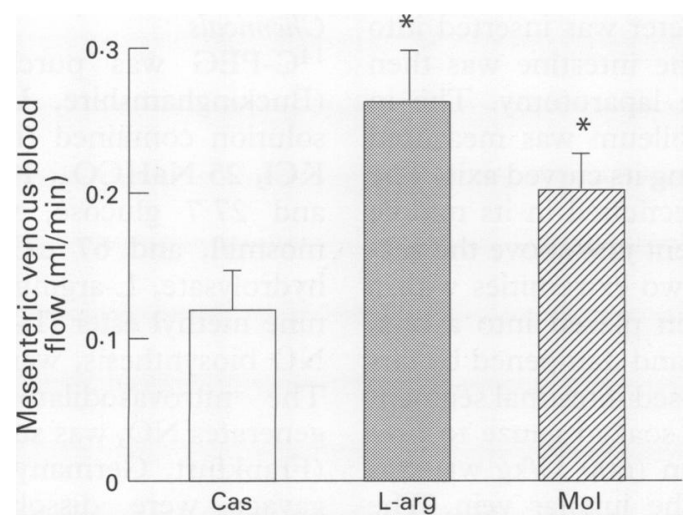

Figure 2: Effect of pretreatment with casein hydrolysate (Cas), L-arginine (L-arg), and molsidomine (Mol) on mesenteric venous blood flow in rats subjected to ischaemialreperfusion. Each value represents the mean (SEM) of five to eight animals. Comparison to Cas* (SEM) of five to eight animals. Comparison to Cas
$p<0 \cdot 05$. Value of sham operated group was $0.27(0.05)$ $p<0 \cdot 05$. Value
$\mathrm{mL} / \mathrm{min}, n=4$.

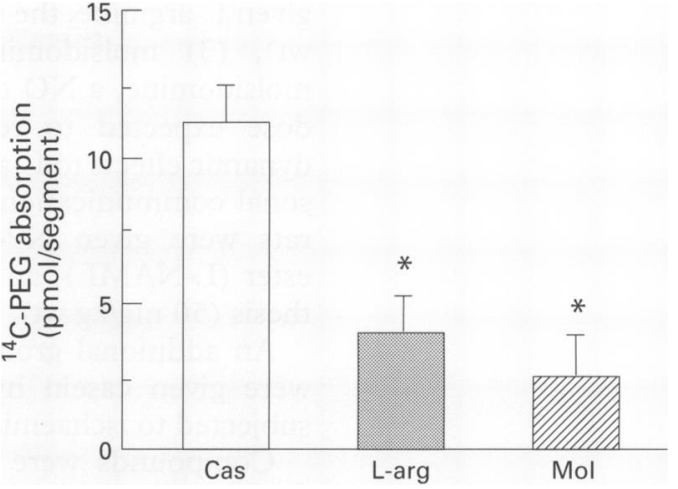

Figure 3: Effect of pretreatment with casein hydrolysate (Cas), L-arginine ( $L$-arg), and molsidomine (Mol) on intestinal barrier permeability (as measured by ${ }^{14} C-P E G$ absorption for the integrated first 10 minute time period) in rats subjected to ischaemia/reperfusion. Each value represents the mean (SEM) of five to eight animals. Comparison to Cas ${ }^{*} p<0.05$. Value of sham operated group was $2 \cdot 1(0 \cdot 4) \mathrm{pmol} / \mathrm{segment}, n=4$.

pretreated with L-arginine and molsidomine had a lesser amount of ${ }^{14} \mathrm{C}-\mathrm{PEG}$ absorption compared with animals pretreated with casein hydrolysate. ${ }^{14} \mathrm{C}-\mathrm{PEG}$ absorption in the intestine from sham operated animals was 2.07 $(0 \cdot 40) \mathrm{pmol} / \mathrm{segment}(\mathrm{n}=4)$.

Mucosal hydrolase activities

The Table shows the mucosal activities of sucrase and aminopeptidase. There was no significant difference between the three groups of animals indicating that mucosal hydrolase activities were not modified by the various treatments 24 hours after I/R.

\section{Mucosal cGMP content}

Figure 4 illustrates the mucosal content of cGMP. In the L-arginine-I/R group, the mucosal cGMP content was significantly higher than in casein-I/R and molsidomine- $/ / R$ groups.

\section{Discussion}

These data show that enteral pretreatment with L-arginine, the substrate of NO, or molsidomine, a NO donor, improved survival and accelerated the recovery of the intestinal barrier function of the $I / R$ injured mucosa. We present evidence that $\mathrm{NO}$ is responsible for these effects. This hypothesis is further supported by the fact that pretreatment with L-NAME, the well known inhibitor of NO biosynthesis, increased mortality (in this study) and exacerbated mucosal damages occurring after intestinal I/R. ${ }^{16}$

TABLE I Sucrase and aminopeptidase activities of intestinal mucosa after 24 hours of $I / R$ in rats pretreated either with casein hydrolysate, L-arginine or molsidomine. Each value represents the mean (SEM) of five to eight animals.

\begin{tabular}{lll}
\hline Group & $\begin{array}{l}\text { Sucrase } \\
(\text { mU/g mucosa) }\end{array}$ & $\begin{array}{l}\text { Aminopeptidase } \\
\text { (mU/g mucosa) }\end{array}$ \\
\hline Casein hydrolysate & $469(80)$ & $526(74)$ \\
L-arginine & $419(128)$ & $538(107)$ \\
Molsidomine & $434(72)$ & $658(175)$ \\
\hline
\end{tabular}




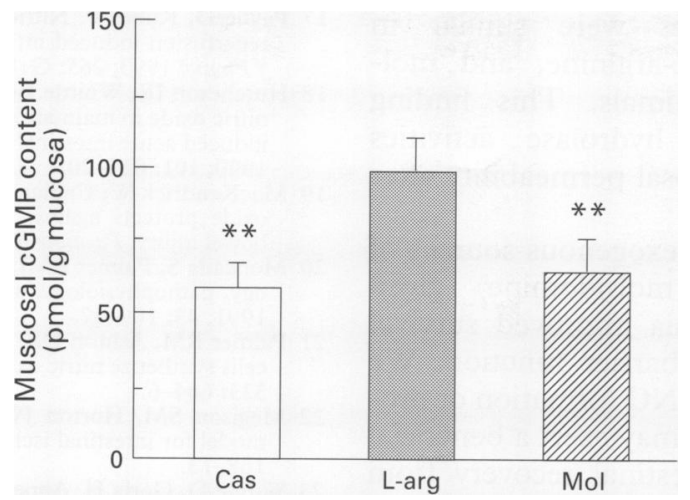

Figure 4: Effect of pretreatment with casein hydrolysate (Cas), L-arginine ( $L$-arg), and molsidomine (Mol) on intestinal mucosal cGMP content in rats subjected to ischaemia/reperfusion. Each value represents the mean (SEM) of five to eight animals. Comparison to L-arg ${ }^{\star *}$ $p<0.01$.

Our results are in agreement with those reported by other investigators who have explored the protective effect of NO. Intravenous infusion of exogenous sources of NO (NO gas in solution and sodium nitroprusside, SNP) improved survival of the cat subjected to I/R. ${ }^{28}$ Inhibition of NO biosynthesis in the rat has been reported to exacerbate the damage to the intestine during endotoxic shock $^{18}$ and PAF treatment. ${ }^{19}$ In addition, inhibition of NO biosynthesis during reperfusion increased the rise in $\mathrm{I} / \mathrm{R}$ induced intestinal permeability in the cat. ${ }^{4}$ Inversely, L-arginine, the precursor of NO, protects the intestine from postischaemic injury by decreasing mucosal and microvascular barrier dysfunction. ${ }^{4}$ Perfusion of NO donors SIN-1, CAS754, and SNP reduced I/R induced mucosal barrier dysfunction in the cat. ${ }^{17}$ Arginine supplemented diet improves survival in gut derived sepsis and peritonitis in the mouse $^{29}$ and the rat. ${ }^{30}$ Finally, in a recent study, we have shown that enteral administration of L-arginine to rats before intestinal $\mathrm{I} / \mathrm{R}$ accelerated morphological and functional recovery of the injured mucosa in the small intestine. ${ }^{16}$

The mechanisms underlying the morphological and functional recovery of the injured intestinal mucosa after I/R are complex and remain unknown. Reduction in intestinal blood flow during reperfusion of the postischaemic intestine has been implicated as a contributing factor to $I / R$ induced mucosal injury. ${ }^{2} 131731$ In this study, there was an increase in mesenteric venous blood flow in L-arginine- and molsidomine- $\mathrm{I} / \mathrm{R}$ animals compared with casein-I/R animals. It is therefore conceivable that the beneficial effect of pretreatment with L-arginine and molsidomine on the recovery of normal mucosal permeability was a result of the ability of these two compounds to prevent the reduction in mucosal blood flow associated with reperfusion of the postischaemic intestine. These data and those reporting that NO increased mesenteric blood flow 3234 support the concept that provision of exogenous NO before $I / R$ may have beneficial properties in mucosal recovery from injury via preventing the reduction in intestinal mucosal blood flow induced by $I / R$. Therefore, the $I / R$ induced mucosal injury may be in part a result of decreased NO activities.

NO is known to activate the soluble guanylate cyclase leading to accumulation of cGMP in the tissues. ${ }^{20}$ cGMP mediates further intracellular signal transduction and results in activation of protein kinases and phosphorylases, which leads to vascular smooth muscle relaxation accounting for vasodilatation. ${ }^{35}$ These data showing that cGMP content in mucosa is increased in L-arginine-I/R animals, indicate that production of NO is increased by pretreatment of L-arginine. This further supports the notion that local release of NO in the intestinal mucosa might be involved in the recovery of normal intestinal permeability. ${ }^{17} 36$

Molsidomine, once absorbed, is converted enzymatically to SIN-1,37 which then releases NO spontaneously. ${ }^{38}$ Previous reports have shown that the vasodilator effects of molsidomine in vivo are mimicked in vessels by relaxing actions of SIN-1. ${ }^{39}$ The latter effects have been attributed to the formation of NO and are mediated by stimulation of guanylate cyclase in vascular smooth muscle cells and hence increasing cGMP values. ${ }^{39}$ The results of this study indicate that mucosal cGMP content in molsidomine- $/ \mathrm{R}$ animals was not increased after 24 hours of I/R. The mechanisms by which molsidomine supports the effects observed in our study remain unclear. However, as intestinal absorption of molsidomine, biotransformation of molsidomine to active metabolites, and NO and cGMP production from SIN-1 occur rapidly, ${ }^{4041}$ it cannot be excluded that the improved mucosal permeability and intestinal blood flow observed in molsidomine treated animals might be mediated through the NO-cGMP pathway.

NO can be generated from L-arginine by two isoforms of the NO synthases (NOS): the constitutive NOS (cNOS), constantly producing small amount of $\mathrm{NO}$ and the inducible NOS (iNOS), which generates large quantities of NO in various stimulated cells. ${ }^{42}$ The cNOS is $\mathrm{Ca}^{2+}$ and calmoduline dependent whereas iNOS is $\mathrm{Ca}^{2+}$ and calmoduline independent. ${ }^{42}$ To evaluate the potential contribution of the two NOS isoforms to the rise in epithelial permeability induced by $\mathrm{I} / \mathrm{R}$, Kanvar and colleagues ${ }^{36}$ quantitated the $\mathrm{Ca}^{2+}$ dependent and independent NOS activity in the injured mucosa of cat small intestine after I/R. Their results show that $\mathrm{Ca}^{2+}$ dependent NOS activity was reduced by $50 \%$ three and four hours of reperfusion, whereas $\mathrm{Ca}^{2+}$ independent NOS activity was undetectable. These data suggest that mucosal dysfunction may be attributed to the inhibition of cNOS activity rather to iNOS.

In a study performed under the same experimental conditions, we have shown that rats pretreated with L-arginine exhibited by four hours of reperfusion a better morphological recovery of the intestinal mucosa and higher hydrolase activities than controls receiving casein hydrolysate. ${ }^{16}$ These data showed that by 24 hours of reperfusion, sucrase and 
aminopeptidase activities were similar in mucosa from casein, L-arginine, and molsidomine pretreated animals. This finding suggest that mucosal hydrolase activities recover faster than mucosal permeability after I/R.

These data show that exogenous sources of NO (L-arginine and molsidomine) given enterally before ischaemia improved survival and intestinal mucosal barrier function. We speculate that increasing NO formation or provision of exogenous NO may exert a beneficial effect by improving intestinal recovery from ischaemic insult.

The authors would like to thank the expert technical assistance of $M$ Galluser, A Nichini, and E Laurent, $R$ Henning of Cassella AG (Frankfurt, Germany) for the generous supply of molsidomine, and Dr B Lutz-Bucher (CNRS URA 1446, Strasbourg, France) for measurement of cGMP content in mucosa.

1 Haglund U, Bulkley GB, Granger DN. On the pathophysiology of intestinal ischemic injury. Clinical review. Acta Chir Scand 1987; 153: 321-4.

2 Granger DN, Sennet M, McElearney PM, Taylor AE. Effect of local arterial hypotension on cat intestinal capilEffect of local arterial hypotension on cat intestinal capil-

3 Schoenberg MH, Beger HG. Oxygen radicals in intestinal ischemia and reperfusion. Chem Biol Interact 1990; 76: 141-61.

4 Kubes P. Ischemia-reperfusion in feline small intestine: role of nitric oxide. Am F Physiol 1993; 264: G143-9.

5 Granger DN, Hollwarth M, Parks DA. Ischemia-reperfusion injury: role of oxygen-derived free radicals. Acta Physiol Scand 1986; 548: S47-63.

6 Parks DA, Bulkley GB. Granger DN, Hamilton SR McCord JM. Ischemic injury in the cat small intestine: role of superoxide radicals. Gastroenterology 1992; 82: 9-15.

7 Johnson LR. Regulation of gastrointestinal mucosa growth. Physiol Rev 1988; 68: 456-502.

8 Otamiri T. Oxygen radicals, lipid peroxidation, and neutrophil infiltration after small-intestinal ischemia and reperfusion. Surgery 1989; 105: 593-7.

9 Kubes P, Kanwar S, Niu X-F, Gaboury JP. Nitric oxide synthesis inhibition induces leukocyte adhesion via superoxide and mast cell. FASEB ₹ 1993; 7: 1293-9.

10 Nillson U, Lundgren O, Haglind E, Bylund-Fellenius A. Radical production during in vivo intestinal ischemia and reperfusion in the cat. Am $\mathcal{F}$ Physiol 1989; 257: G409-14.

11 Hernandez L, Grisham M, Twohig B, Arfors K, Harlan J, Granger DN. Role of neutrophils in ischemia-reperfusioninduced microvascular injury. Am $\mathcal{F}$ Physiol 1987; 253: H699-703.

12 Brown MF, Ross III AJ, Dasher J, Turley DL, Ziegler MM O'Neil JA. The role of leukocytes in mediating mucosa injury of intestinal ischemia reperfusion. $\mathcal{f}$ Pediatr Surg 1990; 25: 214-7.

13 Schoenberg MH, Poch B, Younes M, Schwarz A, Buczako $\mathrm{K}$, Lundberg $\mathrm{C}$, et al. Involvement of neutrophils in postischemic damage to the small intestine. Gut 1991; 32 . 905-12.

14 Otamari T, Lindahl M, Tagesson C. Phospholipase A2 inhibition prevents mucosal damage associated with small inhibition prevents mucosal damage associated with
intestinal ischemia in rats. Gut 1988; 29: 489-94.

15 Salzman A, Wollert PS, Wang H, Menconi MJ, Youssef $\mathrm{ME}$, Compton CC, et al. Intraluminal oxygenation ameliorates ischemia-reperfusion-induced gut mucosa hyperpermeability in pigs. Circ Shock 1993; 40: 37-46.

16 Raul F, Galluser M, Schleiffer R, Gossé F, Hasselmann M, Seiler N. Beneficial effects of dietary L-Arginine on intestinal epithelial restitution after ischemic damage in rats. Digestion 1995; 56: 400-5.
17 Payne D, Kubes P. Nitric oxide donors reduce the rise in reperfusion-induced intestinal mucosal permeability. $\mathrm{Am}$ f Physiol 1993; 265: G189-95.

18 Hutcheson IR, Whittle BJR, Boughton-Smith NK. Role of nitric oxide in maintaining vascular integrity in indotoxininduced acute intestinal damage in the rat. Br 7 Pharmacol 1990; 101: 815-20.

19 MacKendrick W, Caplan M, Hsueh W. Endogenous nitric oxide protects against platelet-activating factor-induced bowel injury. Paediatr Res 1993; 34: 222-8.

20 Moncada S, Palmer RMJ, Higgs EA. Nitric Oxide: physiology, pathophysiology, and pharmacology. Pharmacol Rev 1991; 43: 109-42.

21 Palmer RM, Ashton DS, Moncada S. Vascular endothelial cells synthetize nitric oxide from L-arginine. Nature 1988; 333: 664-6.

22 Megison SM, Horton JW, Chao H, Walker PB. A new model for intestinal ischemia in rat. F Surg Res 1990; 49: 168-73.

23 Winne $\mathrm{D}$, Gorig $\mathrm{H}$. Appearance of ${ }^{14} \mathrm{C}$-polyethylene glycol 4000 in intestinal venous blood: influence of osmolarity and laxatives, effect on net water flux determination. Naunyn Schmiedebergs Arch Pharmacol 1982; 321: 149-56.

24 Dahlquist A. Method for assay of intestinal disaccharidases. Anal Biochem 1964; 7: 18-25.

25 Maroux S, Louvard D, Baratti J. The aminopeptidase from hog intestinal brush border. Biochem Biophys Acta 1973; 321: 282-95.

26 Cailla HL, Racine-Weishbuch MR, Delaage MA Adenosine 3', 5'-cyclic monophosphate assay at $10^{-15}$ mol level. Anal Biochem 1973; 56: 394-407.

27 Koch B, Lutz-Bucher B. Inhibition of protein kinase C activity in cultured pituitary cells attenuates both cAMP independent and -dependent secretion of ACTH. Mol Cell Endocrinol 1991; 77: 57-65.

28 Aoki N, Johnson G, Lefer A. Beneficial effects of two forms of NO administration in feline splanchnic artery occlusion shock. Am f Physiol 1990; 258: G275-81.

29 Gianotti L, Alexander JW, Pyles T, Fukushima R. Argininesupplemented diets improve survival in gut-derived sepsis and peritonitis by modulating bacterial clearance. Ann Surg 1993; 217: 644-54.

30 Madden HP, Breslin RJ, Wasserkrug HL, Efron G, Barbul A. Stimulation of $T$-cell immunity by arginine enhances A. Stimulation of T-cell immunity by arginine enhanc

31 Horton JW, Walker PB. Oxygen radicals, lipid peroxidation and permeability changes after intestinal ischemia and reperfusion. F Appl Physiol 1993; 74: 1515-20.

32 Pizcueta P, Pique JM, Bosch J, Whittle BJR, Moncada S Effect of inhibition of nitric oxide biosynthesis on the systemic and splanchnic circulation of rats with porta hypertension. Br f Pharmacol 1992; 105: 184-90.

33 Iwata F, Joh T, Kawai T, Itoh M. Role of EDRF in splanchnic blood flow of normal and chronic portal hypertensive rats. Am ₹ Physiol 1992; 263: G149-54.

34 Kubes P. Nitric oxide modulates epithelial permeability in the feline small intestine. Am $\mathcal{F}$ Physiol 1992; 262: G1138-42.

35 Brenner BM, Troy JL, Ballermann BJ. Endothelium-dependent vascular responses. Mediators and mechanisms. f Clin Invest 1989; 84: 1373-8.

36 Kanvar S, Tepperman BL, Payne D, Sutherland LR, Kubes $P$. Time course of nitric oxide production and epithelial dysfunction during ischemia/reperfusion of the feline small intestine. Circ Shock 1994; 42: 135-40.

37 Bassenge E, Kukovetz WR, Molsidomine. In: Scriabine A ed. New drugs annual: cardiovascular drugs. Vol 2. New York: Raven Press, 1984: 177-91.

38 Feelisch $M$, Noak $E$. Correlation between nitric oxide formation during degradation of organic nitrates and activation of

39 Kukovetz W, Holzmann S. Cyclic GMP as the mediator of molsidomine-induced vasodilatation. Eur $\mathcal{f}$ Pharmacol 1986; 122: 103-9.

40 Ostrowski J, Resag K. Pharmacokinetics of molsidomine in humans. Am Heart f 1985; 109: 641-3.

41 Kubes $P$. Nitric oxide-induced microvascular permeability alterations: aregulatory role for cGMP. Am F Physiol 1993; 265: H1909-15.

42 Knowles RG, Moncada S. Nitric oxide synthases in mammals. Biochem f 1994; 298: 249-58. 